\title{
Assembling Coordination Frameworks of Tetrakis[meso- (3,5-biscarboxylphenyl)]-Metalloporphyrins with Poly- Nuclear Metallic Nodes: Mechanistic Insights into the Synthesis and Crystallization Process
}

Bharat Kumar Tripuramallu and Israel Goldberg*

School of Chemistry, Sackler Faculty of Exact Sciences, Tel-Aviv University, RamatAviv, $69978 \quad T e l$-Aviv, Israel. E-mail: aryanbharat@gmail.com, goldberg@post.tau.ac.il.

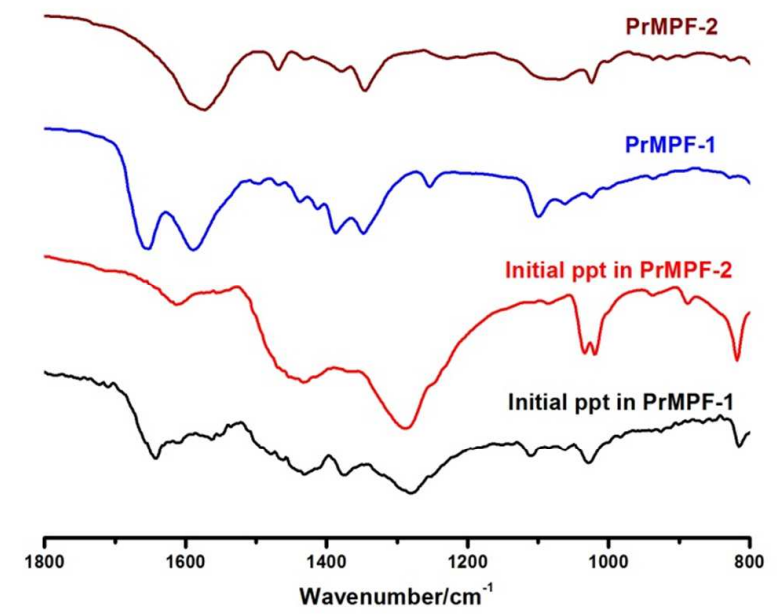

Figure S1. Comparison of IR spectrum of initial precipates formed in the formation of PrMPF-2 and IR spectra of the final crystals of PrMPF-1 and PrMPF-2

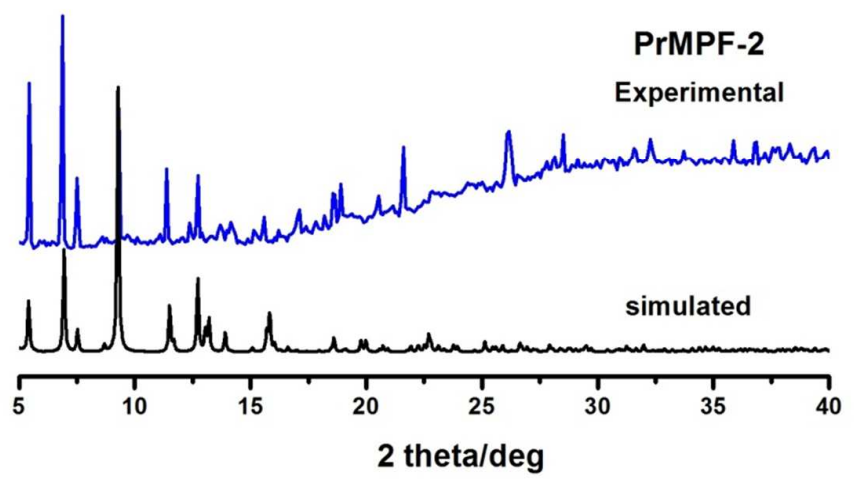


Figure S2. PXRD patterns of PrMPF-2

\section{Figure S3}

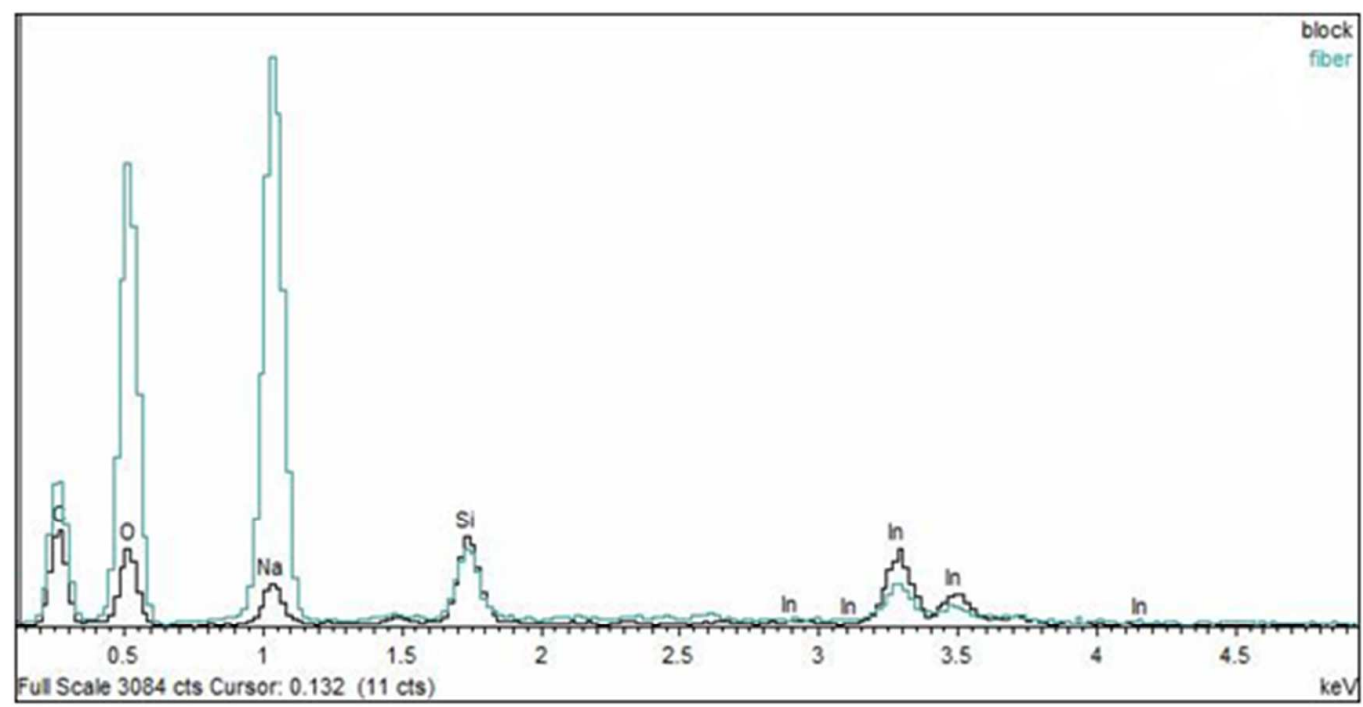

a) Elemental analysis of the corresponding fraction after 3 days (see Figure 1c in manuscript)

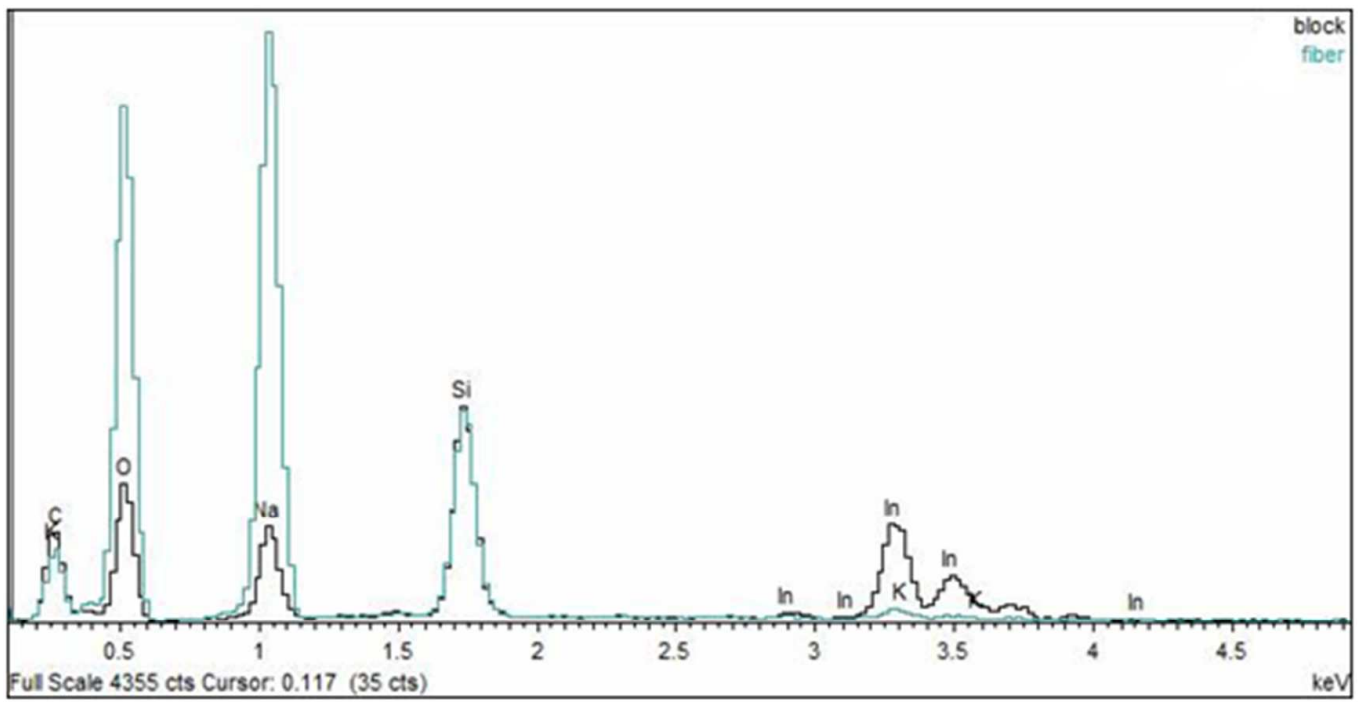

b) Elemental analysis of the corresponding fraction after 6 days (see in Figure 1c in manuscript). 


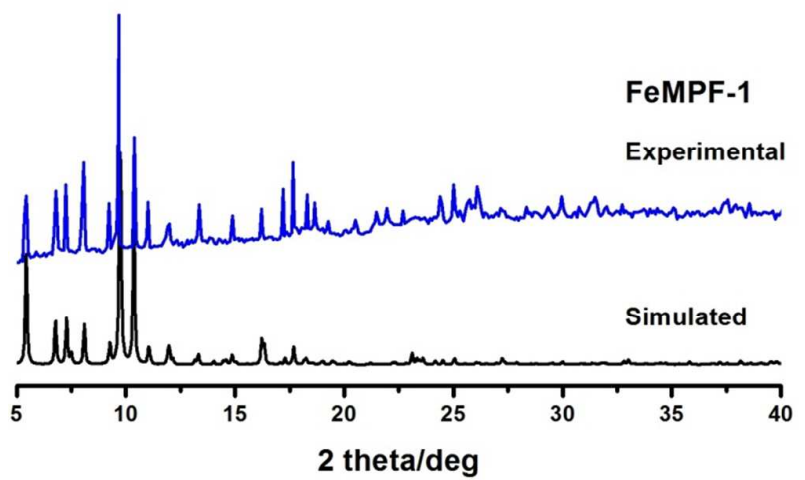

Figure S4. Experimental and crystal-structure-simulated PXRD patterns of FeMPF

Table S1. Complete details of the synthetic methodology

\begin{tabular}{|c|c|c|c|c|c|}
\hline $\begin{array}{c}\text { Metal } \\
\text { Center }\end{array}$ & $\begin{array}{c}\text { Time for } \\
\text { Formation } \\
\text { of Initial ppt }\end{array}$ & $\begin{array}{c}\text { Solubility } \\
\text { of ppt }\end{array}$ & $\begin{array}{c}\text { Formation of } \\
\text { Final } \\
\text { Compound }\end{array}$ & Exchange & Framework \\
\hline $\mathrm{Pr}(\mathrm{III})$ & $3 \mathrm{hrs}$ & Insoluble & 7 days & Yes & PrMPF-1 \\
\hline $\mathrm{Pr}(\mathrm{III})$ & $2 \mathrm{hrs}$ & Insoluble & 7 days & Yes & PrMPF-2 \\
\hline $\mathrm{In}$ (III) & $3 \mathrm{hrs}$ & Insoluble & 8 days & Yes & InMPF \\
\hline $\mathrm{Ga}(\mathrm{III})$ & $24 \mathrm{hrs}$ & Partially & 15 days & Yes & GaMPF \\
\hline $\mathrm{Fe}(\mathrm{III})$ & $3 \mathrm{hrs}$ & Soluble & 10 days & Yes & FeMPF \\
\hline $\mathrm{Mn}(\mathrm{III})$ & $3 \mathrm{hrs}$ & Soluble & 10 days & Yes & MnMPF \\
\hline $\mathrm{Co}(\mathrm{II})$ & $3 \mathrm{hrs}$ & Soluble & 10 days & No & NaMPF \\
\hline $\mathrm{Zr}(\mathrm{IV})$ & $3 \mathrm{hrs}$ & Insoluble & 8 days & No & NaMPF \\
\hline $\mathrm{Al}(\mathrm{III})$ & $3 \mathrm{hrs}$ & Gelatinous & 8 days & No & No crystals \\
\hline $\mathrm{Cr}(\mathrm{III})$ & $3 \mathrm{hrs}$ & Gelatinous & 8 days & No & No crystals \\
\hline
\end{tabular}




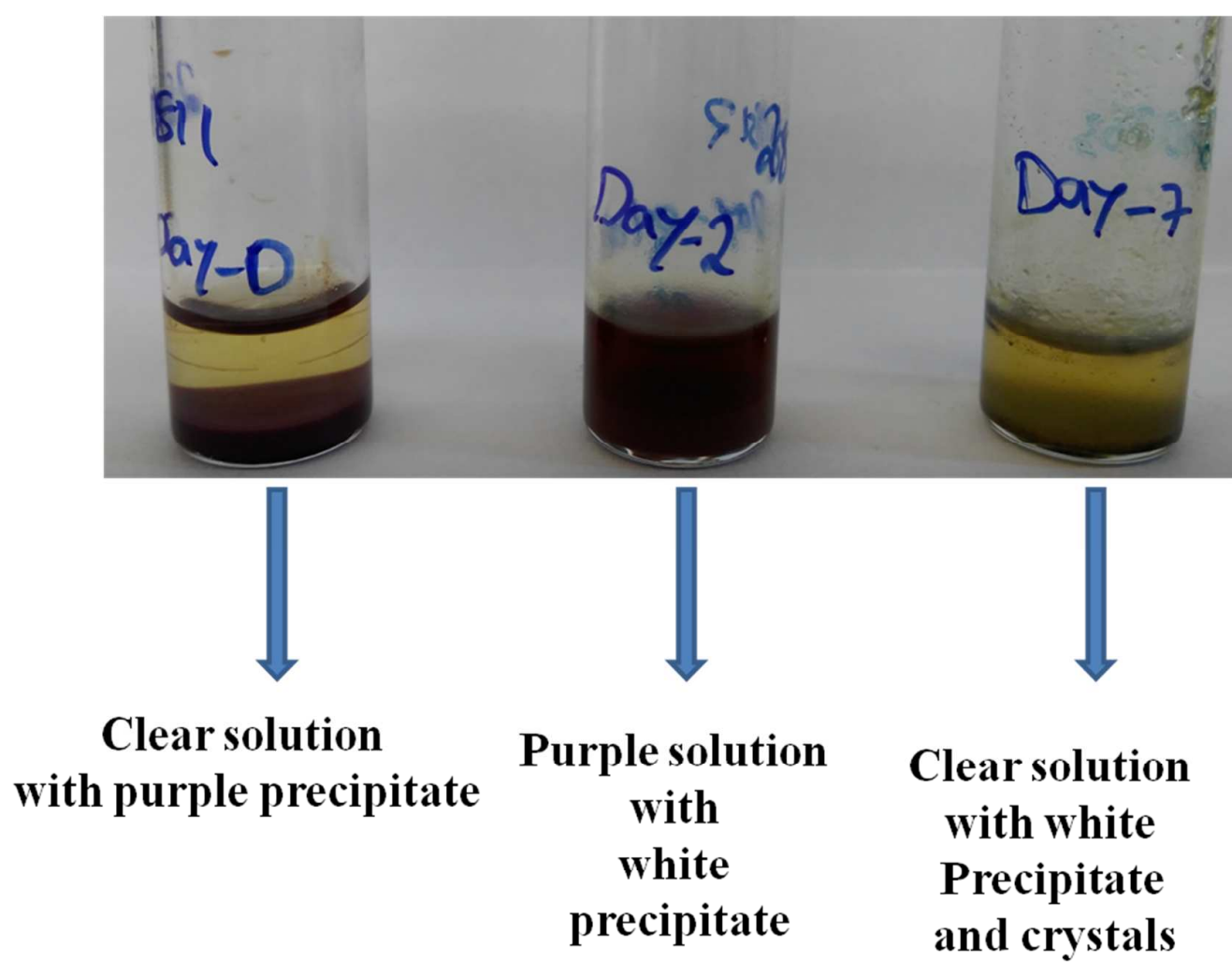

Figure S5. Presentation of the reaction vials at different stages of the reaction with Indium to yield compound $\mathbf{3}$.

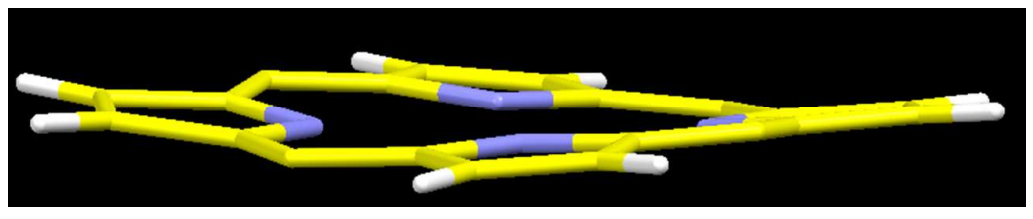

Figure S6. The observed ruffled conformation of metalloporphyrin in PrMPF-2 


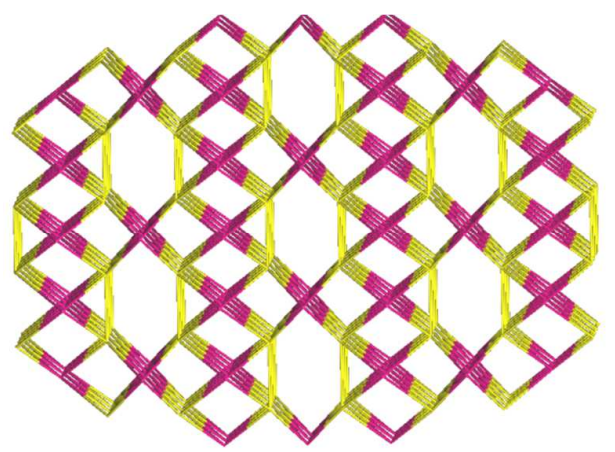

Figure S7. Topological representation of MnMPF (6) by considering $\mathrm{Mn}_{3}$ as node.

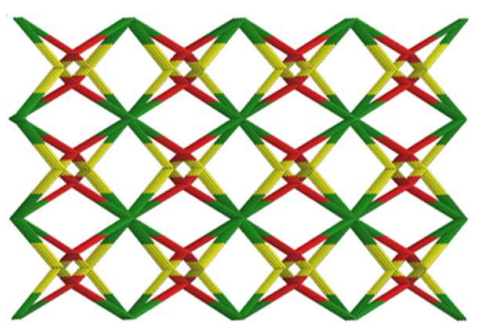

PrMPF-1

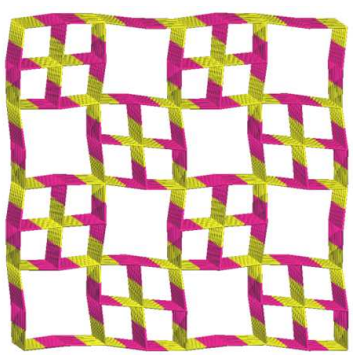

InMPF

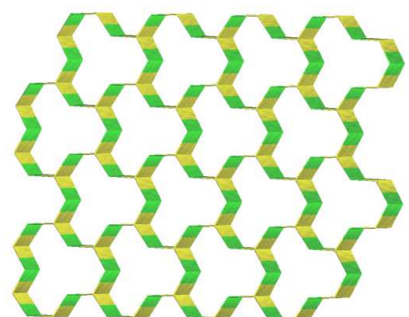

PrMPF-2

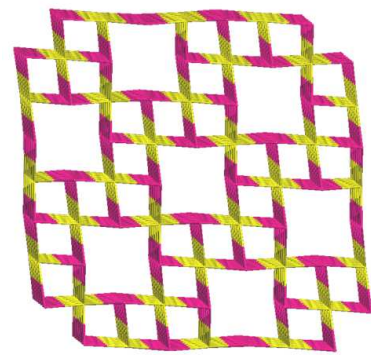

FeMPF

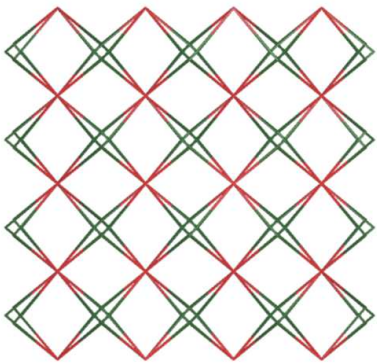

NaMPF-1/2

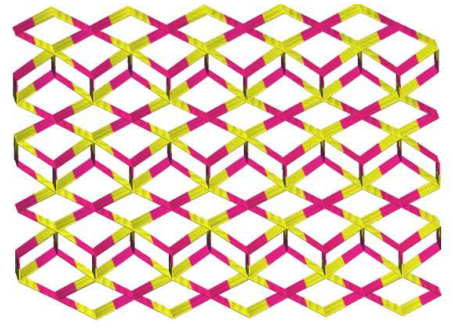

MnMPF

Figure S8 Topological representation of all the analyzed framework materials to visualize the relative disposition and shape of the solvent-accessible channel voids. 